\title{
Marca de ciudad y democratización de la gestión pública
}

Paz, Sergio*

\section{Resumen}

El presente trabajo expone los alcances de una herramienta de gestión que sirviendo al incremento de la competitividad, además se presenta como una instancia privilegiada para la incorporación de la ciudadanía de modo de colaborar con la democratización de la administración pública local. A partir del análisis documental de fuentes vinculadas al marketing urbano y sus desarrollos de marca de ciudad, se definió un recorrido donde el objetivo central es analizar los tres momentos fundamentales en la evolución de la marca de ciudad: creación, desarrollo y gestión, con la preocupación por abrir canales para la incorporación ciudadana en dichos momentos. Se concluye que las acciones de marca de ciudad se convierten en un espacio innovador para ensayar el trazado de canales y mecanismos para la cogestión de las políticas de promoción de las ciudades.

Palabras clave: Administración pública, marca de ciudad, participación ciudadana, democratización.

\section{The City Brand and Democratization of Public Management}

\begin{abstract}
This article presents achievements in the use of a management tool that, while it increases competitiveness, also offers a privileged opportunity for getting the citizenry to collaborate with the democratizing of local public administration. Based on a documentary analysis of sources linked to urban marketing and its development of the city brand, an overview was defined whose central purpose was to analyze three fundamental moments in city brand evolution: creation, development and management, with a concern for opening channels to incorporate citizens in these moments. Finally, based on this theoretical analysis, conclusions are that the city brand is an innovative way to strengthen democratic governance by promoting the city.
\end{abstract}

Key words: Public administration, city brand, citizen participation, democratization.

Recibido: 11-10-06. Aceptado: 20-04-08

* $\quad$ Cand. Doctor en Ciencia Política (Universidad del Salvador, Argentina). Profesor de grado y posgrado (Universidad Nacional de Quilmes, Argentina). Investigador del Proyecto I+D "Gestión, liderazgo y organización de la ciudad en condiciones de complejidad e incertidumbre" (Universidad Nacional de Quilmes, Argentina). E-mail: spaz@unq.edu.ar 
Marca de ciudad y democratización de la gestión pública

Paz, Sergio

\section{Introducción}

La recreación de la agenda de la administración pública en las ciudades integra políticas que deben atender la dinámica desplegada por sus actores en la búsqueda de gobernabilidad, competitividad y habitabilidad.

En este orden, necesitamos que las ciudades utilicen las enseñanzas del cuerpo de la marca de ciudad para cumplir con sus tres objetivos más extendidos: a) fomentar el turismo receptivo, b) la atracción de inversiones y el impulso de las exportaciones, y c) la construcción de ciudadanía (Paz, 2005a). Y será en este último punto donde colocaremos la mirada para este trabajo.

La obsolescencia de ciertas herramientas de la administración pública local lleva la mirada hacia nuevas formas de gestión de lo público, donde se expone la necesidad de integrar al ciudadano a dicho esquema.

Con base en un recorrido por los tres momentos del proceso de evolución de la marca de ciudad, donde se aportan los ingredientes básicos para el desarrollo exitoso de esta herramienta, nos concentramos en la incorporación de la ciudadanía como una exigencia insoslayable.

De allí el interés de este trabajo, cuyo objetivo central es analizar a la marca de ciudad como un espacio que permite colaborar con la apertura de canales de participación ciudadana y la democratización de la gestión pública. La hipótesis de trabajo señala que la marca de ciudad estimula la incorporación del ciudadano, por los excelentes registros que arrojan las instancias que fomentan la creatividad ciudadana. Pero también requiere a la ciudadanía como un actor central, porque la presión social que ejerce en su desarrollo puede hacerla eficiente ya que explicita las aspiraciones de la sociedad y permite mejorar la transparencia y responsabilidad de la gestión pública.

En este sentido, es importante explorar los desarrollos realizados en materia de estrategias de marca de ciudad dado que permite establecer un hilo innovador de conexión con los ciudadanos. Se presenta como una herramienta cuyo proceso de creación y desarrollo permite una gestión pública más democrática, la cual descansa en arreglos institucionales precisos que reparan en canales de influencia ciudadana de modo de construir una mayor viabilidad para la política de promoción de la ciudad.

\section{Nuevos horizontes en la gestión pública local y la marca de ciudad}

La búsqueda de participación, transparencia y equidad se respira en la gestión de los asuntos públicos en las comunidades que transformaron sus gobiernos locales, y con ella una nueva forma de concebir las políticas y sus soluciones. Sabiendo, además, que la búsqueda de gobernabilidad toma como registro la configuración de espacios de participación ciudadana al interior de sus gobiernos.

Hemos experimentado un profundo replanteamiento de los modos de organización de la gestión pública y sus prácticas estratégicas y operativas, dejando un marcado interés por la valoración estratégica de los proyectos, las ventajas en términos de flexibilidad y la eficiencia social a partir de una intervención focalizada. 
En el marco de las nuevas exigencias que impone la agenda actual, la reflexión teórica generó una multiplicidad de nuevos métodos y prácticas abriendo paso a la participación para lograr la viabilidad económica, política, institucional, cultural y social de las políticas que se esgrimen. De esta forma, las políticas locales van a la búsqueda de estrategias que contribuyan a potenciar y afianzar las relaciones entre la ciudadanía y el gobierno, a incrementar la proximidad de los actores sociales y la cooperación públicoprivada.

Este nuevo mundo que se abre camino requiere que se apliquen nuevas recetas, nuevas políticas. $Y$ en este sentido, es importante que rastreemos la utilización de las herramientas del marketing.

\subsection{Aprendiendo de las marcas corporativas}

Un difundido principio dentro del marketing corporativo señala que las empresas venden productos pero comercializan marcas. Para entender esta particular aproximación a este tema debemos decir que el acto de comercializar implica concentrarnos en acciones que estén más allá del producto, trascender al producto.

La marca se ha transformado en la herramienta fundamental que utilizan los gerentes privados para diferenciar sus productos de los de sus competidores. Por ello, una gran cantidad de organizaciones están considerando a sus marcas como sus activos más valiosos, los cuales deben ser desarrollados bajo el cuidado de una gestión que aporte características únicas y distintivas (Davis, 2002).
Es claro que esta definición clásica de marca rápidamente despierta que la marca delimita, identificando a la parte vendedora, y diferencia a los vendedores entre ellos. El incapié en esta distinción que plantea la marca, se debe a el aprecio por las acciones tendientes a la diferenciación (Kotler, 2001).

La palabra brand (marca, en ingles) proviene del vocablo escandinavo $b r a n d r$ que significa quemar, puesto que quemando el ganado, en la antigüedad, un hombre marcaba su propiedad y diferenciaba a sus animales de otros, transmitiendo las funciones primordiales de la marca: identificar y diferenciar a los propietarios. Teniendo un desarrollo que irá otorgando fuerza a la impresión visual del sello, abriendo paso a la marca gráfica desde los albores del industrialismo del siglo XIX. Pero aquella distinción que realzaba el origen, calidad y reconocimiento, en tanto creador, ascendería hasta convertirse en un valor económico ya en el siglo posterior, a la par, que se postulaba como un vector cultural y estético en nuestros días (Blackett y Boad, 2001).

Pero debemos escapar a la concepción que ve en las marcas sólo a su conjunto de atributos, lo cual impulsa una visión centrada en los beneficios funcionales que brindan a los consumidores.

La concepción clásica del marketing se concentró en el desarrollo de productos y servicios, y su definición de marca desacata la voluntad por identificar legalmente a la organización y sus productos. Pero la construcción de una marca como la que pretendemos, en cambio, intenta transformarla en un canal distintivo que une a la ciudad con los deseos y aspi- 
Marca de ciudad y democratización de la gestión pública

Paz, Sergio

raciones de sus consumidores, residentes y no residentes.

Lo cierto es que aquello que da fortaleza a las marcas para competir y ser exitosas son los intangibles: la reputación de la marca en cuanto a calidad, liderazgo, innovación, poder de marca global, son elementos que distinguen a las competidores (Aaker, 1995). Incluso es atendible al interior de la concepción clásica ya que la mayoría de los productos son fáciles de copiar. Sin embargo, es difícil imitar los intangibles de una marca. $Y$ este es un punto esencial en nuestro camino al encuentro de una marca de ciudad que construye ciudadanía.

\subsection{Los componentes esenciales de la marca de ciudad}

El marketing se ha aplicado tradicionalmente a productos y servicios dentro del ámbito corporativo, pero su énfasis en la calidad, satisfacción y competencia se puede transplantar a la ciudad, con lógicas adaptaciones.

Se aborda la cuestión de las marcas de ciudad desde un enfoque crítico que asume la necesidad de las ciudades de contar con nuevos signos de identidad pero salvando la extrapolación simplista de técnicas del marketing corporativo a entidades de naturaleza complejas como son las ciudades (Fernández y Paz, 2005a).

Este enfoque nace en un cuadro signado por la transformación de sus gobiernos locales y una nueva forma de concebir y ejecutar sus políticas. Pero claramente, la difusión en los ámbitos académicos y de la gestión pública local del enfoque del marketing urbano y los desarrollos de marca es una expresión de esa atmósfera propicia para la experimentación innovadora y la búsqueda de miradas no convencionales sobre los fenómenos urbanos (Fernández y Paz, 2005a).

A la pregunta ¿es posible hablar de marca de ciudad? La respuesta emerge con la referencia al valor emocional resultante de las asociaciones que los consumidores hacen de la marca de una ciudad o región, y como su reputación y prestigio intervienen en sus procesos de decisión.

Es cierto que son muchos los países que han apelado al desarrollo de sus marcas con el objetivo de ayudar a los consumidores en dicho proceso, al registrarse como productos con "made in". También es importante el ejemplo de la puesta en escena internacional de las ciudades de España signada por el sol de Miro que postulaba su modernización mostrándola más fresca y competitiva. Elementos como los Juegos Olímpicos celebrados en Barcelona, el Museo Guggenheim de Bilbao, y las películas de Pedro Almodovar, todo confluye en una identidad pujante mostrando que es posible el éxito nacional alimentado por el branding (Gilmore, 2002). Pero la marca de ciudad aquí explorada va más allá, a partir de objetivos más extensos que los que platean este estilo de acciones, estimulados incluso por la flexibilidad y profunda capacidad de adaptación que exhiben las ciudades y comunidades locales.

La marca de ciudad pone en contacto los valores, historia, cultura y una determinada personalidad. La acción de estos elementos o rasgos puede establecer una conexión emocional de la marca con los ciudadanos. Ya no preocupados por los beneficios funcionales que desta- 
quen, el factor diferencial que da esta aplicación de la marca es su poder para dar una fuerte inmunidad frente a la competencia (Paz, 2004).

Los valores intangibles de la marca, cuando se los desarrolla cuidadosamente, se unen para formar una personalidad atractiva que invita a ser compartida en donde conectores como los sentimientos de reputación, orgullo, comunión, compromiso, pertenencia y elevación hacen pie para conectar a la marca con estilos de vida, problemas y actitudes.

Pero antes de seguir explorando las características diferenciales de la marca territorial y los peldaños de su construcción, resta señalar un aporte interesante del marketing corporativo. Bobby Calder y Steven Reagan (2002) señalan que el desarrollo de marca puede enfocarse desde dos visiones: 1) como un desarrollo de marketing o 2) como un desarrollo en la publicidad.

a) Desarrollo centrado en el marketing

La primera de estas aproximaciones destaca a las acciones de marca como parte integral del plan de marketing. Estos planes suelen estar integrados por metas y proyecciones de gastos y ventas que cargan alguna instancia de iniciativa estratégica como consecuencia de las investigaciones sobre el comportamiento de competidores y las tendencias de los consumidores, el entorno competitivo.

De esta forma el componente estratégico se verterá en la marca al explicitarse en las declaraciones acerca de cómo los cambios o correcciones en el rumbo que imprime la marca están a la altura del cumplimiento de metas y objetivos deseados. De esta forma, dichas de- claraciones suelen estar contenidas en la definición de un posicionamiento determinado.

Será el posicionamiento quien de cuenta de las coordenadas que marcan el lugar a conquistar y se convierte en la carta geográfica en la búsqueda de la conexión emocional con los ciudadanos. Todos los esfuerzos estarán concentrados en la búsqueda de un lugar distintivo en sus mentes. Este concepto es la que vuelve a la marca significativa, aquello que enarbola sus virtudes. Pero exploremos estas premisas.

A la base de la filosofía del marketing urbano tradicional se encuentra el dictamen que las ciudades deben estar en contacto con su público meta para atender sus necesidades mediante el desarrollo de nuevos productos y servicios, o la mejora de los procesos organizacionales.

Las recomendaciones del marketing urbano tradicional señalaban que las ciudades debían hacer aquello que el mundo empresarial venía realizando hace mucho tiempo con la formulación de estrategias de marketing estratégico, debían "diseñarse a si misma como un sistema que puede absorber las dificultades y adaptarse rápidamente a nuevos desarrollos y oportunidades" (Kotler et al., 1992: 87).

El concepto último es desarrollar una oferta que logre posicionarse en la mente de los consumidores meta a partir de la percepción de que dichos bienes, y no otros, les proporcionarán beneficios superiores. Toda ciudad necesita desarrollar un posicionamiento distintivo para su oferta buscando como resultado final a la creación de una propuesta de valor enfocada en los beneficios que aporta a los consumidores. 
Marca de ciudad y democratización de la gestión pública

Paz, Sergio

Pero el objetivo buscado en las acciones del marketing actual ya no es entender sus necesidades, deseos y motivos para saber satisfacerlos a partir de productos. Sino esgrimir acciones de marca que conecten emocionalmente a los consumidores (Freemantle, 1998). También es cierto que esta formulación de marca, en un contexto de planificación extrema, termina por ofrecer una declaración de posicionamiento muy abstracta y separada de la esencia de la marca donde sólo aparece una idea general y desdibujada de la marca. dad

b)Desarrollo centrado en la publici-

El otro enfoque que se presenta menos aglutinado y con menos trabajos teóricos es el que aboga por un desarrollo de una marca más funcional que estratégico. Iniciar el camino de desarrollar una marca por un desarrollo de este tipo esta vinculado con establecer que la guía la impondrán los criterios definidos por las agencias de publicidad. Estas agencias cumplirán un papel central al tener que encargarse de definir un slogan de alto impacto en el publico meta, pero que este en orden con la esencia de la marca.

En este contexto serán importantes los desarrollos en términos comunicacionales que se establezcan para dar sentido y unidad a la marca. Aunque debemos señalar que esto no es patrimonio exclusivo de las agencias de publicidad.

Encontramos que varios directivos están convencido que el desarrollo de marca es un problema comunicacional y que los esfuerzos deben estar concentrados en elegir correctamente los colores del logo, o la música, o los lugares en donde se transmitida.

La creatividad es el arma más buscada entre los que abogan por este enfoque ante el convencimiento que un buen anuncio alejado de inspiraciones convencionales y formulas ya utilizadas es el camino que nos asegura el fortalecimiento de la marca.

En este sentido, todas las ciudades deben pasar a una administración consciente de su imagen ya que todas activan asociaciones simplemente con el sonido de su nombre. Sabiendo que la imagen influencia las decisiones de compra, residencia, inversión, ocio y educación, reparan en la publicidad y su mensaje.

Este enfoque presenta el problema inverso al de desarrollo de marca como parte del plan de marketing ya que aquí el mensaje publicitario necesita que la formulación de la marca sea concreta, lo cual ciñe el conjunto de ejecuciones posibles a una determinada batería de herramientas y conceptos.

Presentados estos dos enfoques que dominan los planteos sobre marcas, la tarea que tenemos pendiente es trabajar en una corriente alternativa que rescate los elementos valiosos de ambos pero que subsane las deficiencias descriptas. Esta tercera alternativa estará guiada por concentrarse nuevamente en la esencia de la marca, se trata de un enfoque de creación y gestión de marca centrado en el consumidor.

Como señalan Clader y Reagan (2002), es en su experiencia cotidiana, en sus rutinas y en la experimentación habitual de su casa, trabajo, amigos y recreación, que encontraremos el canal para 
establecer lazos entre la marca y los consumidores. Y esta observación detallada de la vida y personalidad de los consumidores busca un hilo narrativo que pueda coser sus experiencias emotivas.

El reto al cual se enfrenta toda marca es crear fuertes lazos emocionales con el público al cual esta dirigida, particularmente cuando nos encontramos en el camino hacia el encuentro de una marca de ciudad que establezca una conexión entre la ciudad y sus ciudadanos.

Sin embargo, la importancia atribuida a la marca de ciudad para el manejo de las relaciones entre el gobierno y la ciudadanía, las relaciones público-privada y los lazos con otras unidades gubernamentales nos obligan también a emprender el camino hacia la comprensión del proceso de diseño, construcción y gestión de la marca territorial. Proceso que destaca entre sus premisas fundamentales a la necesidad de abrir canales de participación y el establecimiento de mecanismos democratizadores.

\section{El diseño de la marca de ciudad y el rol del ciudadano}

El primer elemento que exige atención en el proceso de diseño de marca es identificar un valor supremo, o al menos significativo e importante, dándole una experiencia más concreta y vivencial al consumidor. Entonces, iremos a la búsqueda de ese dato experimental, ese sentido que sea concreto y ejecutable.

El diseño de marca intentará captar ese sentido subyacente, se trata de una acción sentimental, comprometida y a la vez alejada, es un camino dirigido a la búsqueda de un elemento íntimo y a la vez externo. Con ello, debemos concentrarnos en el dialogo que emprende la marca, en tanto hay un preocupación por escuchar a los consumidores (Calder y Reagan, 2002).

Es importante establecer un dialogo franco y sincero con nuestros consumidores. Y en el caso de las marcas de ciudad, con aquellos que habitan la ciudad. Uno de los principales problemas que tienen los enfoques centrado en el marketing o en la publicidad es que quedan reducidos a la decisión de un grupo pequeño de personas. Pero este es un problema que debe superarse cuando se abordan cuestiones referidos a un ente de naturaleza compleja como son las ciudades.

Este rasgo que dilucidamos es de especial importancia para los desarrollos de marca de ciudad aquí explorado, que tiene entre sus principales preocupaciones: integrar herramientas de participación ciudadana al diseño de marca y establecer mecanismos tendientes a la democratización de su gestión.

\subsection{La participación ciudadana en el diseño de marca}

El desafió que tenemos por delante en esta aventura por abrir canales de participación ciudadana es que las mismos se conviertan en verdaderas venas que puedan trasladar la energía vital presente en la sociedad.

De esta forma iremos al encuentro de enfoques que nos permiten activar el potencial creativo existente en el cuerpo social de manera que los actores locales y ciudadanos se transformen en "co-creadores" del futuro de la ciudad (Nielson, 2000). 
Marca de ciudad y democratización de la gestión pública

Paz, Sergio

Para esto allanaremos el camino recurriendo al trabajo del especialista Friedman (2004) que ha emprendido esfuerzos para identificar técnicas denominadas: Tecnologías de Intervención de Grandes Grupos (IGG). El objetivo de estas técnicas es emprender caminos de cogestión en tiempo real, generando participación efectiva de los ciudadanos bajo la premisa de activar la creatividad colectiva ${ }^{1}$.

Si bien cada una de las estás técnicas tiene particularidades que las describen como verdaderos paquetes de herramientas a los cuales podemos recurrir para saciar nuestras necesidades en orden con los objetivos e intereses que tengamos, podemos decir que el conjunto de las IGG trabaja con el concepto del fractal, y las experiencias realizadas intentan colocar a todos los ciudadanos bajo un sistema abierto donde discuten y consensuan qué se quiere y cómo se logra, implicándolos en la formulación real de la política y gestión publica local.

Una de estas técnicas más utilizadas es el Open Space Tecnology dado que el círculo, el ágora y el panel son sus mecanismos básicos. No se incluyen discursos ni ponencias y no hay una agenda predefinida. La agenda de trabajo es elaborada en el mismo momento en que se realiza el evento por los mismos participantes. Cada participante puede propo- ner temas, se discuten en profundidad en talleres a los que cada asistente se integra libremente operando la ley de los dos pies. Los resultados de los talleres son recopilados y reproducidos en tiempo real en un Reporte Ciudadano.

De esta forma, las IGG no sólo es un instrumento para la gestión urbana, sino que integran un canal para impulsar una ciudad en permanente aprendizaje, movilizando la creatividad ciudadana y recuperando el compromiso de los ciudadanos (Friedman, 2004).

\section{El proceso de creación de la marca de ciudad}

Hemos observado que varios de los conceptos extraídos de la teorías del management corporativo necesitan ser digeridos a la luz de los diferenciales preocupaciones, responsabilidades y objetivos que tiene la política y gestión local.

Para la marca de ciudad, debemos reparar un momento en la diferenciación entre las marcas funcionales, de imagen y de experiencia otorgada, Tybout y Carpenter (2002) para las marcas corporativas.

En este sentido, las marcas de imagen y de experiencia se encuentran más cercanas a nuestros intereses ya que abogan por establecer una conexión emocional con los consumidores. Estas

1 Reinhardt Friedman (2004) señala que actualmente se puede identificar una serie de técnicas de IGG: Tecnología de Espacio Abierto (Open Space Tecnology); Conferencia de Búsqueda (Search Conference); Conferencia de Búsqueda del Futuro (Future Search); Conferencia de Indagación Apreciativa (Appreciative Inquiry Summit) Conferencia de Cambio Estratégico en Tiempo Real (Real Time Strategic Change); Modelo de Conferencia (The Conference Model); Diseño Participativo (Participative Design); Simulación Real (Simu-Real). 
marcan construyen su valor proyectando una imagen y suelen ser utilizadas para categorías de productos que son difíciles de ser evaluados. El conjunto de imágenes asociadas a la marca es lo que define el carácter único de la marca, creando símbolos que son valorados. Las marcas de experiencia sólo destacan una cuestión de énfasis. Mientras que las marcas de imagen se centran en los productos y los personajes que despiertan un conjunto de asociaciones deseadas, las de experiencia recaban en las experiencias que sienten los consumidores cuando entran en contacto con las marcas.

La mayor particularidad es que las marcas de experiencia integran un escenario en donde productos, servicios y entornos se dan crean encuentros multisensoriales con la marca. $Y$ puede ser que una marca de este tipo sea experimentada de diferente forma; cuestión de especial relevancia en el caso de las ciudades, regiones y comunidades.

Uno de los desafíos más importantes para la gestión de la marca de ciudad es otorgar coherencia a la gran gama de experiencias que se ofrece bajo su halo. Puesto que conviven debajo suyo un extenso número de experiencias con poder y espacios distintos, e incluso dirigidas a agentes diferentes.

En desarrollos anteriores de marcas territoriales relacionados con la expansión de las exportaciones y el fomento del turismo, señalamos que la marca territorial es una construcción que explota el valor emocional resultante de las asociaciones que los consumidores hacen de dicha marca. Detrás de esta decisión se encuentra la conexión emocional que existe entre el consumidor y el lugar que patrocina el producto a través de su marca (Paz, 2005a, 2005b). Estos planteos estaban vinculados con la búsqueda de un equilibrio entre la marca de imagen y desarrollos de marca de experiencia puesto que, por las cuestiones públicas que se deseaban atender, se necesitaba establecer una conexión emocional entre los consumidores y la marca de ciudad.

Creemos que en el marco de la preocupación actual, la tarea que tenemos por delante es redoblar la apuesta y concentrarnos en la creación y construcción de una marca de ciudad asociadas a las de experiencia. Así, la comercialización de comunidades, ciudades y regiones a través de sus marcas, se presenta como una exigencia ante el aprovechamiento de las asociaciones que despiertan los lugares con su gente, ideas, estilos de vida, comida y fiestas tradicionales.

Pero el esfuerzo por sumar consumidores que crucen la puerta de la conexión emocional, haciéndola portavoz de sentimientos y aspiraciones personales, se establece a partir de una excitante relación de amor, odio, traición, infidelidad, regocijo, placer, orgullo, alegría y decepción entre las agencias gubernamentales y el conjunto de ciudadanos.

Ahora es momento de pasar a los aspectos que debemos tener en cuenta para guiar el proceso de gestión de la marca de ciudad.

\section{Los cinco pasos en la gestión de la marca de ciudad}

Un esquema de gestión permitirá desarrollar una marca fuerte pero el camino para generar una conexión con los consumidores requiere de inventiva, inte- 
Marca de ciudad y democratización de la gestión pública

Paz, Sergio

gridad y tenacidad en el proceso de evolución de la marca.

El camino propuesto pone a la luz la búsqueda de la esencia la marca de ciudad, y la senda la recorreremos a través de cinco conceptos centrales. Cada uno de estos se convierten en exigencias que se imponen al modelo de gestión de la marca de ciudad, el cual guarda la preocupación por sumar a los ciudadanos a partir de mecanismos de participación y democratizadores, además de sustentar un avance progresivo en la búsqueda de fortaleza para la marca.

\section{- Primer paso: Visión de marca}

El camino hacia la gestión de marca de ciudad debe iniciarse con una profunda comprensión de sus aspiraciones y objetivos que tienen los ciudadanos respecto a su ciudad, es decir, la visión de marca.

En el mundo de los negocios, la visión de marca se convirtió en la declaración más importante que una organización puede formular respecto a sus metas y objetivos estratégicas de modo de maximizar el valor y mejorar las utilidades. Sin embargo, aún es normal encontrar cierta desconfianza respecto al poder de este tipo de declaraciones en otros ámbitos, perdiéndose de vista los beneficios de estos planteos al exigir una comprensión acabada de la actividad, el mercado y el público meta.

De esta forma, la visión de marca que es una declaración que establece de forma clara y simple las guías para comenzar a transitar el camino de la gestión de marca territorial en las acciones tendiente a crear ciudadanía, a la par que fo- menta sus actividades económicas fundamentales.

\section{- Segundo paso: Identidad de marca}

Una identidad clara y eficaz debe estar vinculada a la visión de marca, y a los valores, atributos y rasgos de la ciudad que se quieran transmitir. Ya no abogamos porque los bienes de la ciudad ofrezcan variedad, calidad y durabilidad, sino que la meta buscada es que los consumidores de la ciudad, residentes y no residentes, perciban que dichos productos y servicios permite decir algo de su propia vida, su personalidad.

La búsqueda de este vínculo emocional en donde el consumo público se exterioriza en valores y creencias que son deseables, no es una tarea sencilla. La tarea que tiene por delante la marca territorial es ayudar a los ciudadanos a sentir confianza, orgullo, valentía, felicidad, audacia, honestidad, solidaridad en la práctica cotidiana en la ciudad.

La definición de la identidad de la marca estará supeditado a la aprehensión de dos elementos: a) la imagen de marca, y b) el contrato de marca. Primero, la imagen de marca orientará el desarrollo de estrategias que profundizaran las fortalezas y apalancaran la marca dado que la aprehensión de su imagen permite dilucidar las percepciones y la correlación entre las asociaciones de marca que realizan y la ciudad. Para ello es fundamental explorar las asociaciones que la marca despierta, es decir, las imágenes y sensaciones que destellan en los sentidos con cada experimentación.

También alcanzar una imagen positiva requiere la construcción de un per- 
sonaje de marca haciéndola más cercana a los ciudadanos. El personaje de marca es el conjunto de características humanas con que la que los consumidores asocian a la marca: personalidad, apariencia, género, edad, talla, etnia, clase socioeconómica, educación, entre otras, todo confluye para dar vida a un personaje, a partir del cual deciden si quieren ser asociados con una marca determinada de la misma forma que quieren ser asociados con algunas personas y no con otras.

Segundo, tenemos el contrato de marca que se presenta como un listado de las promesas que una marca hace a sus ciudadanos y consumidores de los productos de la ciudad, y estas pueden estar en constante redefinición integrando algunas nuevas o revalidado otras, pero siempre cuidando que estos cambios no lesionen la confianza depositada. El contrato de marca, en tanto se define internamente y se valida externamente, ayuda a cernir el canal de las expectativas de los ciudadanos, a la par, que obliga a los estrategas de marca a ser honestos. Las partes contrayente de este contrato, de este acto, quedan comprometidas a velar por el cumplimiento de la responsabilidad y objetivos que contrajeron.

Esta búsqueda de su personalidad, de descubrir sus elementos íntimos, permitirá establecer la ciudad que se desea alcanzar.

\section{- Tercer paso: Posicionamiento de marca}

El posicionamiento de la marca de ciudad es el lugar deseado a alcanzar, es aquel valor que se quiere alcanzar cuando se piensa en la marca. Debe ser espe- cífico, relevante y audaz en su planteamiento pero servil a las necesidades de los ciudadanos.

Pero debemos alejarnos de la definición de posicionamiento vinculada a la caracterización funcional que aboga por una definición cerrada del mercado meta, de la actividad y de los beneficios diferenciales como los tres elementos que deben integrar la expresión (Arnold, 1998).

Aunque quedan intactas las exigencias, es necesario que esté reglado por un conjunto de cuatro principios que marcará el ritmo y acusará necesidades respecto a su reposición o conservación: a) la necesidad de articulación con la estrategia general permitiendo una redefinición sistémica ante necesidades internas y externas, 2) la necesidad de liderazgo vinculado al hecho que debe marcar la dirección a la estrategia de marca en general, 3) la necesidad de compromiso permitiendo a este proceso mantenerse vital y con confianza, bajo el objetivo que la gerencia y los empleados se vuelvan embajadores de la marca, y 4) la necesidad de atención a las percepciones y necesidades de los ciudadanos (Aaker, 1995).

Es preciso que señalemos que el posicionamiento reclamado al interior del proceso de gestión de marca territorial integrará una especial preocupación porque ese lugar o valor deseado represente las aspiraciones de los ciudadanos.

\section{- Cuarto paso: Cultura de marca}

La aventura por crear un marco para la gestión de la marca de ciudad ha permitido esclarecer que la única forma de lograr un crecimiento sostenido de su poder, es logrando la formación de una 
Marca de ciudad y democratización de la gestión pública

Paz, Sergio

cultura que abogue por cumplir con los objetivos del desarrollo de marca.

En el marco de la marca territorial, la práctica del trabajo cotidiano estaría acompañada por el incremento del orguIlo, el reconocimiento y la motivación. La creación de una cultura estratégica de marca para la ciudad, región o comunidad local alimenta un proceso en el que cada uno se identifica como miembro, en el que cada uno es parte (Fernández y Paz, 2005b).

Hay que trabajar intensamente para lograr el compromiso y la consagración de todos los agentes implicados en la satisfacción de las necesidades y aspiraciones. El camino está signado por la búsqueda de metas y valores compartidos. La disposición mental compartida a la cual apelamos está más allá de la referencia a una comprensión común acerca de la forma de ejecutar un trabajo, sino que buscamos una construcción de una cultura que exprese el sentido de la marca de ciudad.

La construcción de una cultura de marca necesitará de canales de comunicación interna para socializar la importancia del desarrollo de la marca territorial al interior de la organización encargada o el entramado institucional responsable de su gestión, pero también de comunicación externa al destacar que la participación sostiene dicho proceso.

\section{- Quinto paso: Mensaje de marca}

La comunicación interna y externa de las acciones de marca es vital para expandir sus posibilidades de éxito. Para ello debemos trabajar en impulsar un cambio de comportamiento, hablando de iniciativas, propuestas y prioridades a través de un esquema eficaz de políticas de comunicación.

Un elemento de particular importancia en el diseño de estrategias de comunicación de marca es la persecución de los mismos principios que han reglado el arribo al corazón de la marca y la pasión que reclama para sí. Una recomendación insalvable es que todas las estrategias de comunicación deben estar en línea con el logro de los objetivos propuestos. De esta forma, la visión, la identidad y el posicionamiento de marca ayudarán a definir la estrategia de comunicación.

Hay que entender que la creación de la marca es más que la mera comunicación y que esta es sólo una herramienta dentro del esquema de gestión de una marca de ciudad exitosa. Desafortunadamente, en muchos espacios persiste la idea que un anuncio televisivo o las tareas de las agencias de publicidad bastan para asegurar el cumplimiento de las estrategias de marca.

La gestión de una marca de ciudad que tenga entre sus objetivos a la construcción de ciudadanía necesitará un trabajo conciente en sus canales de comunicación tendientes a reforzar la marca en orden a los objetivos e intereses de los ciudadanos.

Los conceptos centrales de la marca de ciudad aquí presentados han expuesto la necesidad de integrar al ciudadano a la concepción, definición y ejecución de las acciones de marca. Ya hemos observado que en el proceso de diseño de marca exploramos lo imperioso que resulta establecer canales de participación de ciudadana, pero resta que seña- 
lemos también la necesidad de contar con mecanismos democratizadores en su gestión.

\subsection{La necesidad de la democratización de la gestión}

La democratización de la gestión pública significa convertir a la ciudadanía en un sujeto directo de control. Existe un extendido reconocimiento al valor que tiene democratizar a la gestión pública debido a la injerencia cada vez de los intereses políticos sobre los funcionarios públicos que son sometidos a seguir prerrogativas partidarias (Cunill, 2000). $Y$ en el caso de la marca de ciudad, estamos en presencia de una política que requiere de un plazo considerable para su maduración de modo de apreciar sus frutos.

La separación del esquema administrativo de las influencias políticas coyunturales puede sustentar la implementación de esta política para la promoción de las ciudades y comunidades. Pero, claramente, esta pretensión reclama profundizar la democracia en su seno, convirtiendo a la ciudadanía en un actor relevante que canaliza su influencia a favor de resultados mejores y más equitativos.

Como señala De Sousa Santos (2005: 91-95), necesitamos una articulación entre la democracia representativa y la democracia participativa puesto que la novedad es que la obligación política vertical entre Estado y ciudadano ya no puede asegurar por si sola los valores de la cooperación, solidaridad y democracia.

En este sentido, la idea de una ciudadanía activa se presenta como uno de los requisitos para la actual gestión pública, cuestión que ya destacamos al presentar la necesidad de asegurar los canales de participación ciudadana.

Nos encontramos en un contexto en donde los principios clave de la participación política, esto es, la igualdad y el pluralismo político, deben ser asegurados expresamente por los mecanismos de participación directa (Cunill, 2004).

No sólo estamos dirigiendo la mirada hacia canales abiertos para captar y expresar la opinión ciudadana para la gestión de la marca de ciudad, sino que llevamos la atención sobre las ventajas que carga incluso la coproducción. Pero para ello será necesario que se establezcan canales de diálogo permanente a partir de arreglos institucionales al interior de las sociedades (Paz, 2007).

La gestión de marca de ciudad permite construir un gobierno societal, destacando la emergencia de renovados arreglos institucionales que permiten desarrollar nuevos esquemas de control.

Será necesario que se establezcan canales de participación, y que entendamos que no hay posibilidad de emprender un verdadero proceso de democratización, sí la ciudadanía no se convierte en un actor político con una actuación activa y crítica. Así, puede pensarse en esquemas de representación o coproducción con organizaciones del tercer sector con base solidaria y extendidas modalidades de control social que exijan transparencia (Cunill, 2004).

La marca de ciudad tiene como elemento específico y necesario para dinamizar sus virtudes a la democratización de la administración pública al actuarse 
Marca de ciudad y democratización de la gestión pública

Paz, Sergio

sobre su diseño, construcción y gestión. Esta idea exige dotar de auténticos medios para que la ciudadanía pueda influenciar directamente el sistema de políticas locales.

\section{A modo de conclusión}

Hemos encontrado que en el marco de las exigencias que impone la agenda actual en las ciudades, regiones y comunidades locales, se generaron una multiplicidad de nuevos métodos y prácticas abriendo la necesidad de incorporar instrumentos de participación ciudadana y mecanismos de democratización de la administración pública. De esta forma, la política y gestión local intentan contribuir a extender y fortalecer las relaciones entre el gobierno y la ciudadanía, como la cooperación público-privada.

Estas nuevas políticas y prácticas deberán reparar en la construcción y administración de la marca de ciudad debido a sus poderosas virtudes para cumplir con dichos objetivos. Los desarrollos de la marca de ciudad integran acciones de política y gestión pública que están concebidos para abonar el sentimiento de pertenencia y sentido colectivo entre los ciudadanos.

Luego de reparar en la necesidad imperiosa de abrir canales de participación ciudadana para el diseño de marca, escapando a los principios tecnicistas que reservan dicho proceso a un grupo pequeños de expertos. Entendemos a la marca de ciudad como un constructo sociohistórico, de ahí la necesidad imperiosa de sumar al ciudadano para que se sienta completamente cercano y comprometido con la marca desde su concep- ción, pero la tarea de la ciudadanía no se termina en dicha instancia.

Es necesario pensar en la necesidad de la participación ciudadana en las instancias de decisión sobre la marca de ciudad, pero también puede pensarse en esquemas de coproducción como formas de control ciudadano, ante las exigencias que impone el clima actual.

Resulta necesario establecer mecanismos tendientes a democratizar su gestión, llevándonos a un verdadero estadio de cogestión de la política de promoción de las ciudades. Creemos que la gestión de la marca de ciudad permite construir un gobierno con arreglos institucionales que desarrollan un control de los ciudadanos sobre ellos mismos, en la medida que la presión social puede mejorar la eficiencia y la transparencia.

\section{Referencias Bibliográficas}

Aacker, David (1995). Building Strong Brands, New York, Free Press.

Arnold, David (1998). Manual de la gerencia de marca, Bogota, Norma.

Blackett, Tom y Boad, Bob (2001). Cobranding. La ciencia de la alianza, Buenos Aires, Pearson Educación.

Calder, Bobby y Reagan, Steven (2002). "Diseño de marca", en lacobucci, Dawn (comp.), Marketing según Kellogg, Buenos Aires, Vergara.

Cunill Grau, Nuria (2000). "Responsabilización por el control social”, en Bresser Pereira, Luiz y Cunill Grau, Nuria (eds.), La Responsabilización en la Nueva Gestión Pública Latinoamericana, Buenos Aires, EUDEBA-CLAD.

Cunill Grau, Nuria (2004). "La democratización en la administración pública. Los mitos a vencer", en Bresser Pereira, Luiz 
et. al., Política y Gestión Pública, México, Fondo de Cultura Económica-CLAD.

Davis, Jeff (2002). La Marca. Valor máximo de su empresa, México, Pearson Educación.

De Sousa Santos, Boaventura (2005). Reinventar la democracia. Reinventar el Estado, Buenos Aires, CLACSO.

Fernández, Gabriel y Paz, Sergio (2005a). "Más allá del Marketing de ciudad. La marca territorial como herramienta para la participación ciudadana", Scripta Nova, $N^{\circ} 194$, Universidad de Barcelona, España.

Fernández, Gabriel y Paz, Sergio (2005b). "Marca territorial, Identidad y Participación Ciudadana", Revista Abaco, $N^{\circ} 21$, Valladolid, España.

Freemantle, David (1998). Lo que les gusta a los clientes de su marca, Bilbao, Ediciones Deusto.

Friedmann, Reinhardt (2004). "Urban Management by complexity. Nuevas formas de gestión estratégica urbana y de participación ciudadana", en Fernández, Gabriel y Leva, German (eds.), Lecturas de economía, gestión y ciudad, Buenos Aires, Universidad Nacional de Quilmes Ediciones.

Gilmore, Fiona (2002). "A Country: Can it be Repositioned? Spain: the Succes Story of Country Branding", Journal of Brand Management, Vol. 9, pp. 34-42.
Kotler, Philip (2001). Dirección de Marketing, México, Pearson Educación.

Kotler, Philip, Haider, Donald y Rein, Irvin (1994). Mercadotecnia de localidades, México, Editorial Diana.

Nielson, Greg (2000). Self-Governance in Communities and Families, San Francisco, Berrett-Koehler.

Paz, Sergio (2004). "Marca Territorial. Como construir y administrar la marca de ciudades y regiones", en Fernández, Gabriel y Leva, German (eds.) Lecturas de economía, gestión y ciudad, Buenos Aires, Universidad Nacional de Quilmes Ediciones.

Paz, Sergio (2005a). Marca Territorial. Valor para la política de promoción comercial, Buenos Aires, Politike Ediciones.

Paz, Sergio (2005b). "Gestión estratégica y posicionamiento de ciudades. La marca de ciudad como vector para la proyección internacional", Revista Venezolana de Gerencia, Año 10, № 30, Universidad de Zulia, pp. 177-195.

Paz, Sergio (2007). Reforma en la Administración Pública, Buenos Aires, Politike Ediciones.

Tybout, Alice y Sternthal, Brian (2002). "Crear y administrar marcas", en lacobucci, Dawn (comp.), Marketing según Kellogg, Buenos Aires, Vergara. 